\title{
PARENTS INVOLVED IN COMMUNITY SCHOOLS V. SEATTLE SCHOOL DISTRICT NO. 1 ET AL. E MEREDITH, CUSTODIAL PARENT AND NEXT FRIEND OF MCDONALD V. JEFFERSON COUNTY BD. OF ED ET AL. (2007) $)^{1}$
}

\author{
IVAR ALBERTO MARTINS HARTMANN ${ }^{2}$
}

O debate público acerca de Ações Afirmativas é relativamente recente no Brasil. Apenas na última década foram implantados os primeiros planos que incorporam cotas raciais e sociais para o acesso a algumas universidades. Da mesma forma, a lei federal que estipula a adoção destes e outros mecanismos similares de inserção da população negra na sociedade ainda está tramitando. Sequer a jurisprudência, que de maneira geral inova enfrentando de antemão assuntos frescos e polêmicos, manifestou um paradigma: a ação que questiona a constitucionalidade de lei estadual carioca versando sobre a matéria ainda não foi julgada pelo Supremo Tribunal Federal ${ }^{3}$.

É natural, portanto, que pesquisadores brasileiros interessados no tema foquem sua atenção em experiências estrangeiras, mais maduras e longevas ${ }^{4}$. Muito embora o caso indiano e o sul-africano sejam ambos de grande valia para o estudo das ações afirmativas, freqüentemente se finda por analisar o caso norte-americano. A despeito de contarem menos idade que na Índia, os programas de ações afirmativas nos Estados Unidos evoluíram muito desde que o presidente Kennedy incitou os americanos a medidas pró-ativas de combate à discriminação racial. Tanto quanto a doutrina, a jurisprudência daquele país oferece aos estudiosos do assunto valorosa contribuição.

As políticas públicas ou privadas de alavancamento de minorias socialmente desfavorecidas com o intuito de concretizar a igualdade material são utilizadas hoje para garantir o acesso ao trabalho, a mandatos políticos, à moradia, e a outros bens da vida. Aqui faremos resenha de uma decisão da Suprema Corte Norte-americana

\footnotetext{
${ }^{1}$ A decisão pode ser encontrada no seguinte endereço: http://www.supremecourtus.gov/opinions/06pdf/05-908.pdf ${ }^{2}$ Acadêmico de Direito da PUC-RS.

${ }^{3}$ Tramita perante a Corte a ADI $n^{\circ} 3.197$, proposta pela Confederação Nacional dos Estabelecimentos de Ensino, em que se questiona a constitucionalidade da Lei ${ }^{\circ} 4.151 / 2003$, do Estado do Rio de Janeiro, que institui sistema de quotas nas universidades estaduais daquela entidade federativa - UERJ e UENF.

${ }^{4}$ Para um estudo de políticas de ações afirmativas em diversos lugares do mundo, ver SOWELL, Thomas. Affirmative action around the world: an empirical study. New Haven, C.T.: Yale University, 2004.
} 
que julgou a validade de dois programas de desegregação racial no ensino público. A maioria das ações afirmativas implementadas nos Estados Unidos têm como pilar de sustentação a decisão do caso Bakke em 1978. Mas enquanto essa jurisprudência multi-citada permitiu a adoção, pelas universidades, de sistemas de seleção de alunos utilizando o critério racial, foi a decisão do caso Brown, em 1954, que marcou o início de feroz combate ao racismo nas escolas de nível fundamental e intermediário. Em Brown, a Suprema Corte determinou o fim da doutrina "separate but equal (separados porém iguais)” vigente desde o caso Plessy, em 1896. Ao invalidar a segregação racial em escolas, em virtude da violação que tal sistema infringia à $14^{\mathrm{a}}$ Emenda Constitucional, a Corte afirmou que diferenciar crianças brancas de negras no ambiente de ensino afrontava o direito das crianças negras à Igual Proteção da Lei. Na verdade, subsiste até os dias atuais discussão entre aqueles que entendem que a decisão do caso Brown procurava banir qualquer uso do critério "raça” pelo poder público, principalmente em se tratando de direito à educação, e aqueles que enxergam na decisão da Suprema Corte um mandame de integração racial e, conseqüentemente, de elevação do ensino prestado às crianças negras à qualidade daquele prestado às crianças brancas. Tal questão é suscitada inclusive no presente julgamento. Qualquer que seja a ratio impingida a Brown, o fato é que se seguiu a esta decisão um movimento nacional voluntário de implantação de políticas de desegregação racial nas escolas, acompanhado em igual patamar por uma jurisprudência ávida em decretar a desegregação forçada nas unidades de ensino cujos administradores não a realizaram por conta própria.

Esse é o cenário onde se coloca a presente decisão da Suprema Corte Norteamericana. A desegregação racial no ensino de nível fundamental e médio foi crescente da década de 50 até a década de 80, passando a enfraquecer, de maneira variada, mas no país inteiro, a partir daí ${ }^{5}$. Hoje, assim como os sistemas de ações afirmativas relacionados ao acesso à universidade, as políticas públicas implementadas pelas escolas para remediar o apartheid histórico sofrem de baixa popularidade, tornando sua manutenção cada vez mais difícil. A opinião pública norte-americana manifesta-se contrária a adoção de medidas especiais para a minoria negra na realização do direito fundamental à educação ${ }^{6}$. As ações afirmativas sociais, por outro lado, obtêm maior aceitação ${ }^{7}$. Nesse contexto, muitos noticiam o presente julgamento da Suprema Corte como uma rápida revisão do standard assentado recentemente na decisão do caso Grutter v. Bollinger (2003) ${ }^{8}$. Enquanto naquele caso foi reafirmado o princípio estabelecido em Bakke pelo Justice Powell, de que as universidades podem adotar a raça como critério na admissão de

\footnotetext{
${ }^{5}$ Parents v. Seattle School District, Justice Breyer. 551 U.S. 4 (2007). Ver ainda o anexo do voto de Breyer para dados estatísticos.

${ }^{6}$ Ver o diagnóstico feito por Dworkin da atual situação nos Estados Unidos em DWORKIN, Ronald. Sovereign virtue: the theory and practice of equality. Cambridge, Mass: Harvard University Press, 2000. pg. 386.

7 Para obter argumentos qualificados da doutrina norte-americana em favor das ações afirmativas sociais, ver KAHLENBERG, Richard. Economic Affirmative Action in College Admissions: A Progressive Alternative to Racial Preferences and Class Rank Admissions Plans. Disponível em: http://www.tcf.org/list.asp?type=PB\&pubid=88. Acessado em: 27.07.2007.

${ }^{8}$ Uma análise detalhada desta decisão pode ser encontrada em TUSHNET, Mark. Regras da Corte Suprema Norte-americana sobre ação afirmativa. In: SARLET, Ingo W. (Coord.). Jurisdição e Direitos Fundamentais: anuário 2004/2005, t. 2. Porto Alegre: Livraria do Advogado, 2005.
} 
estudantes, sendo a diversidade ${ }^{9}$ um interesse governamental compulsório ${ }^{10}$, aqui estaria a Corte pacificando o entendimento de que a raça não deve ser motivo de qualquer diferenciação utilizada pelo Estado. Conforme opiniões mais adiantadas, as ações afirmativas nos Estados Unidos estariam próximas de seu fim.

O presente julgamento apreciou conjuntamente uma ação de uma associação sem fins lucrativos - que reúne pais de Seattle descontentes com o programa de desegregação - contra o distrito educacional número 1 da mesma cidade, no estado de Washington, e uma ação de Crystal Meredith contra o comitê de educação do condado de Jefferson, no estado de Kentucky. As autoridades governamentais responsáveis pela educação fundamental e intermediária nessas localidades utilizavam planos voluntários de desegregação racial. Em Seattle, estudantes eram alocados nas escolas de ensino médio mais procuradas conforme um critério racial, buscando equilíbrio. Da mesma forma, em Louisville, no condado de Jefferson, a raça era fator que auxiliava a colocação dos alunos nas escolas ainda no ensino fundamental, bem como determinava decisões sobre pedidos de transferência entre escolas.

O distrito educacional número 1 de Seattle permitia que os alunos ingressando na nona série listassem por ordem de preferência as escolas onde gostariam de estudar. Algumas escolas mais populares mereciam a escolha de um número de alunos maior que aquele que poderiam receber. A determinação de quais alunos tinham sua opção atendida era feita, então, mediante a aplicação de uma série de três critérios de desempate ${ }^{11}$. O primeiro era a existência de um irmão já cursando aquela escola. O segundo critério era o racial. Em todo o distrito educacional havia $41 \%$ de alunos brancos e 59\% de não-brancos (essa era a nomenclatura dada aos negros, hispânicos, índios e asiáticos). Se a porcentagem de alunos brancos ou não-brancos de determinada escola encontrava-se fora de um raio de $10 \%$ acima ou abaixo da média do distrito, tal escola era considerada "integração-positiva”, e não recebia alunos que fossem agravar o desequilíbrio racial. Por exemplo, se um aluno branco e um negro listassem como sua primeira opção uma escola cuja freqüência era de 55\% brancos e $45 \%$ não-brancos, no caso de nenhum dos dois ter um irmão já matriculado na escola, ao branco seria negada a matrícula, sendo colocado então em sua segunda ou terceira opção de escola. O aluno negro, por sua vez, seria aceito na escola, contribuindo para o decréscimo na alta porcentagem de brancos existentes. Caso o segundo método de solução do empate não fosse suficiente, aplicar-se-ia o terceiro, residencial, sendo aceito o aluno que morasse mais próximo do estabelecimento.

Em Louisville o problema guardava uma característica que, embora comum a diversos estabelecimentos educacionais norte-americanos, não era encontrada no distrito educacional de Seattle. Nos anos setenta o judiciário havia reconhecido que as escolas

\footnotetext{
${ }^{9}$ Um bom estudo sobre a "diversidade do corpo discente" como interesse governamental das instituições de ensino, bem como a mais abrangente pesquisa do resultado das ações afirmativas nos Estados Unidos desde Bakke pode ser encontrada em BOWEN, William G. O curso do rio: um estudo sobre a ação afirmativa no acesso à universidade. Rio de Janeiro: Garamond, 2004.

${ }^{10}$ No original, compelling governmental interest. Embora o verbo da língua inglesa "to compel” possa ser traduzido para “compelir”, o adjetivo que julgamos mais próximo no vernáculo é “compulsório”.

${ }^{11}$ Voto do Justice Roberts, pg. 3.
} 
do condado de Jefferson praticavam segregação racial de jure, sendo determinado que tal prática fosse remediada através de um programa compulsório de desegregação. O programa adotado inicialmente sofreu diversas alterações e evoluiu significativamente, apresentando um quarto de século depois uma conformação lapidada especificamente para a situação daquele local. Em 2000, entretanto, o judiciário dissolveu o decreto que havia instituído anos antes, entendendo que o distrito de Jefferson havia tomado todas as medidas necessárias para a erradicação da segregação racial, eliminando no maior nível possível os traços da prévia discriminação ${ }^{12}$. Sendo assim, em 2001 o distrito educacional implantou um programa voluntário de combate à segregação, justamente aquele impugnado pela ação aqui analisada. No condado de Jefferson as crianças são associadas a uma determinada escola, denominada "reside", conforme sua residência. As escolas são organizadas em grupos, dentro do território abrangido pelo programa, de maneira a facilitar a integração. Crianças da região que desejam matricular-se no jardim de infância ou primeira série, ou ainda aquelas novas ao distrito que desejam ingressar em alguma das escolas, listam sua primeira e segunda opção de instituição de ensino. A alocação dos alunos é feita então observando os critérios residencial e racial. Segundo o critério racial, devem ser observadas em cada escola as porcentagens mínima de $15 \%$ e máxima de $50 \%$ de alunos negros. A autora da ação, Crystal Meredith, tentou matricular seu filho no jardim de infância de determinada escola - mais próxima de sua casa que aquela indicada inicialmente pelas autoridades de ensino - e teve seu pedido negado em razão do adverso efeito da transferência no cumprimento da desegregação ${ }^{13}$.

As ações questionando a constitucionalidade dos programas voluntários de desegregação de Seattle e Jefferson frente à Cláusula de Igual Proteção da $14^{\mathrm{a}}$ emenda à Constituição Norte-americana foram decididas nas instâncias imediatamente inferiores em desfavor dos autores. A sucumbência foi revertida na Suprema Corte.

O presidente da Corte, Chief Justice Roberts, produziu o voto condutor, considerado a opinião da corte. Ao seu voto, que invalidou os programas educacionais, aderiram os Justices Scalia, Alito e Thomas. Este último redigiu voto separado, concordando com o Chief Justice. O Justice Kennedy dissentiu em parte da visão majoritária, expondo em voto independente seus motivos, porém aderiu à decisão, votando também pela invalidação dos programas. O Justice Breyer votou de maneira contrária a esta maioria, no que foi seguido pelos Justices Ginsburg, Souter e Stevens. Este último produziu curto voto concordando com a posição divergente. Trata-se, assim como em grande parte das decisões da Suprema Corte relacionadas às ações afirmativas, de escore apertadíssimo.

O Chief Justice Roberts inicia seu voto assegurando a competência da Corte para julgar os casos em questão. Entendeu ele existir um dano causado pelos distritos educacionais aos autores, decorrente da obrigação a que estes últimos são submetidos de sujeitarem-se a um processo de competição que utiliza critérios raciais ${ }^{14}$.

\footnotetext{
${ }^{12}$ Voto do Justice Roberts, pg. 7.

${ }^{13}$ Idem, pg. 9.

${ }^{14}$ Idem, pg. 10.
} 
Como é de praxe na Suprema Corte Norte-americana, antes de analisar o mérito da questão - no caso, a constitucionalidade dos programas de segregação - determina-se o standard de controle de constitucionalidade que será aplicado. Há três deles, sendo o mais rigoroso aquele chamado de estrito escrutínio. Conforme o precedente ventilado em casos anteriores e sedimentado no caso Adarand, em 1995, sempre que a questão sob apreço envolva uma classe suspeita, como são denominadas as maiorias ${ }^{15}$, o controle de constitucionalidade da lei impugnada deve ser o mais rigoroso possível. A classificação com base na raça é entendida como "por demais perniciosa"16 para aceitar um controle leniente. Isso significa que qualquer discriminação só restará justificada se o poder público, ou ente agindo em função deste, proceder visando um interesse governamental compulsório (compelling governmental interest) e assim o fizer de maneira perfeitamente configurada à situação (narrowly tailored). Tal rigorismo já havia sido criticado pelo Justice Marshall no caso Fullilove v. Klutznick (1980), por implicar em um controle estrito em teoria, porém fatal na prática ${ }^{17}$. Alguns entendem tratar-se de controle rigoroso em demasia, o que terminaria por invalidar qualquer plano de ações afirmativas ou desegregação racial. O Justice Breyer sustentou em seu voto que não deveria ser aplicado ao caso o estrito escrutínio. Segundo ele, não se trata de programa governamental que distribui bens escassos entre diversas pessoas, como no caso do acesso ao ensino superior, mas sim da alocação de diferentes alunos em escolas de igual qualidade. Entretanto, após defender a aplicação de um controle estrito diferenciado ${ }^{18}$, em razão das particularidades do caso em questão, o Justice resigna-se à aplicação do estrito escrutínio, procedendo em seu voto à análise dos programas de Seattle e Jefferson conforme os requisitos compreendidos por este nível de controle constitucional. O voto condutor do Justice Roberts, bem como o independente, do Justice Kennedy, propugnaram de plano pela aplicação do estrito escrutínio, seguindo o precedente firmado em Adarand.

O Justice Roberts indicou de início que a discriminação racial como aquela efetuada no caso em questão é aceita somente mediante a indicação de um interesse governamental compulsório, e que tal foi aceito anteriormente pela Corte em apenas duas situações. Primeiramente, para remediar os efeitos de prévia discriminação maligna realizada através do Estado. Tal uso do critério racial justificou-se, conforme o entendimento de Roberts, em muitas situações verificadas nos estabelecimentos de ensino logo após Brown. Apenas quando é detectada a segregação de jure praticada pela máquina estatal, ou ente agindo em nome dela, pode o Estado utilizar mecanismos de reversão dessa situação que utilizem a raça como critério. Todavia, para o

\footnotetext{
${ }^{15}$ As minorias - no sentido sociológico e não populacional - são aqui entendidas como "classes suspeitas" em razão da suspeita geral de que leis que as diferenciem, por qualquer motivo, são a priori inconstitucionais frente à Cláusula de Igual Proteção. Pertinente lembrar que políticas públicas discriminando benignamente o gênero feminino, também considerado classe suspeita, são submetidos ao controle intermediário de constitucionalidade.

${ }^{16}$ Fullilove v. Klutznick, 448 U. S. 448, 537 (1980) (Voto do Justice Stevens).

${ }^{17}$ Para considerações de diversos autores americanos sobre a aplicação do estrito escrutínio nos casos de ações afirmativas, ver GARVEY, John H. Modern constitutional theory: a reader. 4. ed. St. Paul, Minn: West Group, 1999. pg. 609

${ }^{18}$ Voto do Justice Breyer, pg. 36.
} 
Chief Justice essa situação de maneira nenhuma se apresentava em Seattle e Jefferson. Enquanto Seattle jamais havia praticado segregação de jure, Jefferson havia sido contemplada em 2000 com o reconhecimento de seus esforços no sentido de remediar a discriminação racial maligna. A dissolução do decreto que obrigava ao programa de desegregação foi entendida pelo voto vencedor como a sinalização da inexistência de presente discriminação de jure em Jefferson. Assim, restaria impossível o reconhecimento, tanto no caso de Seattle, como de Jefferson, de um interesse governamental compulsório no sentido de remediar os efeitos de prévia segregação racial.

O Justice Breyer discordou com veemência de tal assertiva. Segundo ele, seria incoerente afirmar que o programa de desegregação mantido pelas escolas de Jefferson era constitucional em um dia e inconstitucional no outro ${ }^{19}$. Ademais, acrescentou, é impróprio determinar a diferença entre segregação de facto e de jure com base apenas em uma decisão judicial ordenando a desegregação. Em muitos casos, distritos educacionais que por anos haviam praticado o apartheid apressaram-se em voluntariamente reverter seus efeitos, motivo pelo qual o judiciário não havia tido a oportunidade de manifestar-se sobre o assunto. Esse seria o caso de Seattle, cujas práticas haviam sido questionadas judicialmente em diversas ocasiões. As iniciativas do próprio distrito educacional em remediar a situação pré-Brown obtiveram sucesso em evitar um decreto como aquele ao qual fora submetido o condado de Jefferson. Tanto Roberts como Kennedy, contudo, percebem a dissolução judicial do decreto como interrompendo a obrigatoriedade da remediação, e não como reconhecendo uma modificação instantânea da situação de fato detectada nas escolas.

Associados a questão da percepção da segregação de jure ou de facto encontram-se os comentários de Breyer sobre a impertinência de tal diferenciação. Para o Justice, tal dicotomia interessa apenas quando se está analisando a existência de uma obrigação constitucional de remediar os efeitos do racismo legal, mas não quando se está avaliando a existência de uma permissão constitucional de desegregação. Apenas nesse ponto Kennedy acompanha o voto vencedor, entendendo que a Constituição permite que as autoridades responsáveis pela educação escolar adotem, voluntariamente, programas de desegregação racial ${ }^{20}$. Tanto esse Justice, em seu voto independente, como Breyer, no voto acompanhado pela minoria, sustentam existir uma diferença entre a discriminação racial benigna, visando incluir, e a discriminação racial maligna, visando excluir. Para Roberts e Thomas, tal diferenciação é perigosa porque reside justamente em uma percepção sociológica baseada no entendimento histórico de cada época, que não pode ser imputada à Constituição ${ }^{21}$.

\footnotetext{
${ }^{19}$ Idem, pg. 56.

${ }^{20}$ Kennedy permanece mais próximo da opinião majoritária, contudo, no que tange a uma diferenciação entre segregação de facto e de jure. Voto de Kennedy, pg. 15. O Justice é cauteloso, igualmente, quanto à aplicação do critério racial direto nas chamadas discriminações benignas: "The idea that if race is the problem, race is the instrument with which to solve it cannot be accepted as an analytical leap forward.”. Idem, pg. 17. Ele sustenta o uso de métodos de desegregação que não associem diretamente cada indivíduo a uma raça, motivo pelo qual julgou que os programas de Seattle e Jefferson não passam pelo testo da estrita conformação, como será visto mais adiante.

${ }^{21}$ Voto do Justice Roberts, pg. 35.
} 
O Chief Justice assegura que Breyer incorre em erro ao confundir a segregação de facto com mero desequilíbrio racial nas escolas. Para ele, embora esse último possa eventualmente ser o resultado de prévia segregação de jure, tal situação tende a tornar-se cada vez mais escassa, diante dos esforços empreendidos no sentido de erradicar a nefasta prática na seara do ensino. O desequilíbrio racial nas escolas resultaria então de fatores sociais como o local de residência, não importando em conseqüências constitucionais. Da mesma forma, rejeitando o alerta feito por Breyer de que ocorre no momento nos Estados Unidos uma resegregação racial nas escolas, em virtude justamente da invalidação de muitos planos educacionais que se baseiam em critérios raciais, Roberts afirma que quando a resegregação é fruto não da ação estatal, mas de escolhas privadas, ela não tem implicações constitucionais ${ }^{22}$. No mesmo sentido, Thomas afirma que nada a não ser um interesse em estética da sala de aula e uma hipersensitividade às suscetibilidades da elite justificam os programas de balanceamento racial dos distritos escolares ${ }^{23}$.

Como se vê, o voto de Roberts, acompanhado pela maioria da Corte, negou a existência de um interesse governamental compulsório em remediar os efeitos de prévia discriminação, diante da inexistência de segregação de jure em Seattle e Jefferson. O outro interesse governamental reconhecido como obrigatório, em casos de discriminação racial, é aquele apontado pela primeira vez em Bakke e confirmado no último precedente relacionado às ações afirmativas, Grutter v. Bollinger (2003). Tanto para Roberts como para Thomas, o interesse reconhecido pela Suprema Corte em Grutter diz respeito exclusivamente ao ensino superior. O contexto importa quando se trata do estrito escrutínio, e as universidades americanas merecem tratamento diferenciado em razão de sua função constitucional, relacionada com a liberdade de expressão ${ }^{24}$.

Aqui há dois pontos que podem ser analisados em separado. O primeiro é esse já dissecado: para a maioria da Corte, o ensino superior tem características diferenciadas, associadas à expansão de certos direitos, mormente a liberdade de expressão, daí porque a busca pela diversidade nesse nível de educação encontra-se justificada. Breyer posiciona-se de maneira contrária. Para ele, se a diversidade é importante a nível universitário, muito mais importante o é a nível escolar, pois se trata de educar os norte-americanos nos aspectos da pluralidade racial e étnica desde a mais tenra idade ${ }^{25}$.

O segundo ponto é aquele que diz respeito a uma “deferência” da Suprema Corte para com os estabelecimentos de ensino. No voto condutor o Justice Roberts afirma que tal consideração deve ser alcançada apenas às universidades, justamente em razão de seu papel constitucional diferenciado. Para o Chief Justice, não se pode estender

\footnotetext{
${ }^{22}$ Idem, pg. 28.

${ }^{23}$ Voto do Justice Thomas, pg. 4 (em nota de rodapé). O Justice deixa transparecer uma posição impassiva diante da realidade social, quando afirma que a Suprema Corte não deve ajudar a criar uma sociedade que inclui todos os americanos, ou resolver a “problemática escolar urbana”. Idem, pg. 20.

${ }^{24}$ Voto do Justice Roberts, pg. 16. Thomas posiciona-se da mesma maneira, pg. 25 de seu voto.

${ }^{25}$ Voto de Breyer, pg. 41. Cita então as palavras do já aposentado Justice Thurngood Marshall, que disse:

“A não ser que nossas crianças comecem a aprender juntas, há pouca esperança que nossas pessoas algum dia aprendam a viver juntas”.
} 
tal voto de confiança às demais autoridades responsáveis pela educação. A utilização de critérios raciais é extremamente delicada e já foram constatados diversos casos em que a discriminação foi utilizada de maneira nefasta, sob o véu da pretensa "integração". Thomas chega ao ponto de afirmar que não abriria mão de sua função de guarda da Constituição em favor das autoridades administrativas escolares ${ }^{26}$. Mas o Justice Breyer garante que os distritos escolares e as comissões responsáveis, formadas geralmente tanto por funcionários públicos como pais, devem sim ser aqueles que determinam a formatação de planos de desegregação racial. Estas pessoas conhecem as particularidades de suas regiões e suas escolas e trabalharam durante anos como é o caso de Seattle e Jefferson - modificando e adaptando seus programas educacionais, tanto voluntários como obrigatórios, para chegar ao seu objetivo. Breyer afirma que não é um juiz o melhor capacitado para estabelecer um plano de integração racial dentro de uma escola ${ }^{27}$.

Breyer cita um precedente que está ligado à questão da deferência para com as escolas. Para ele, ficou assentado no caso Swann, em 1971, que as autoridades escolares possuem amplo poder para formular e implementar políticas educacionais ${ }^{28}$. Para Roberts, contudo, tal precedente não existe, pois essa opinião que embasaria os argumentos do voto minoritário havia sido ventilada em sede de obiter dictum, ou seja, não estava associada ao exame do mérito daquele processo, mas apenas ilustrava a decisão. Como tal, não manifestava o entendimento da Corte e não poderia ser considerado um precedente de obrigatória aplicação ${ }^{29}$. Além do mais, assegura Roberts, tal decisão foi emitida antes do estabelecimento da obrigatoriedade do estrito escrutínio para análise da constitucionalidade da adoção de critérios raciais. Breyer responde que o voto condutor tenta estabelecer diferenças exageradamente técnicas e desnecessárias, como meio para mascarar sua posição extremada no presente caso ${ }^{30}$. Assegura que os precedentes posteriores a Swann estabeleceram o estrito escrutínio, mas não um escrutínio fatal, pelo qual nenhuma política pública passaria. Breyer lembra novamente que o contexto deve ser considerado, e o contexto aqui não é o de distribuição entre diversos indivíduos de um bem da vida que existe em pouca quantidade. Trata-se, isso sim, de distribuir alunos em estabelecimentos substancialmente similares.

Em seu voto, após defender inicialmente um exame de constitucionalidade mais brando, Breyer passa a testar os programas educacionais em questão através do estrito escrutínio. Para ele, o interesse de Seattle e Jefferson, que denomina “integração", era um interesse governamental compulsório. Divide essa noção de integração em três aspectos. O primeiro é a necessidade de remediar práticas históricas de discriminação

\footnotetext{
${ }^{26}$ Voto de Thomas, pg. 20.

${ }^{27}$ Voto de Breyer, pgs. 48 e 62.

28 “Autoridades escolares estão tradicionalmente investidas de amplo poder para formular e implementar políticas educacionais e podem muito bem concluir, por exemplo, que para preparar estudantes para viver em uma sociedade pluralística cada escola deve ter uma proporção prescrita de estudantes negros para brancos refletindo a proporção do distrito como um todo. Fazer isso como uma política educacional está incluído nos amplos poderes discricionários das autoridades escolares.”Chief Justice Burger, no caso Swann (1971) 402 U. S. pg. 16.

${ }^{29}$ Voto de Roberts, pg. 30.

${ }^{30}$ Voto de Breyer, pg. 30.
} 
maligna, que excluíram durante séculos os negros. O segundo é educacional e tem com a obrigatoriedade de reverter os aspectos negativos ligados ao ensino em ambientes racialmente segregados. O terceiro e último é democrático: um interesse em reproduzir nas salas de aula o ambiente pluralista e multirracial com os quais as crianças deparar-se-ão na sociedade ${ }^{31}$.

Em seu voto, o Justice Thomas dedica-se longamente a desconstrução destes três aspectos perfilados por Breyer. O primeiro aspecto do interesse, a remediação dos efeitos da prévia segregação, é contestado, pois como já havia sido mencionado, a maioria da Corte entende não existir no momento segregação de jure em nenhum dos dois distritos educacionais. O que estaria sendo combatido era, sim, o desequilíbrio racial. Este se afigura, no entanto, como um fundamento por demais amorfo para permitir reparação com base em diferenciação racial. Por outro lado, como o desequilíbrio racial depende de fatores sociais, manifesta-se de maneira infinita e jamais poderia ser anulado. Assim, faltaria um ponto final lógico aos programas que visassem proporcionar o balanceamento racial ${ }^{32}$. Já as vantagens proporcionadas por um ambiente escolar multirracial foram contestadas por Thomas com base em diversas obras doutrinárias. Para ele, a relação entre aproveitamento escolar e integração racial é muito tênue para sustentar o uso de um critério racial pelo poder público. Ademais, cita diversas instituições de ensino exclusivamente negras que obtêm resultados excelentes ${ }^{33}$. Por último, o Justice descarta a existência de um interesse legítimo em diversidade racial escolar diante da inexistência de provas de que uma composição racial variada na sala de aula provoque uma otimização das relações inter-raciais no futuro ou diminua os conflitos entre negros e brancos. Para Thomas, sequer é possível provar que colocar negros e brancos no mesmo estabelecimento garantirá sua efetiva convivência mútua. Adiciona ainda que, assim como uma busca pela correção do desequilíbrio racial, o interesse em diversidade racial nas instituições de ensino não tem um ponto de parada, faltando-lhe o requisito de temporariedade das políticas de ações afirmativas ${ }^{34}$.

As críticas da maioria são respondidas por Breyer novamente através da distinção entre aquilo que os distritos educacionais devem e aquilo que podem fazer com o intuito de proporcionar a diversidade e a desegregação racial. E, com relação à controvérsia apresentada na literatura especializada sobre a questão pedagógica da integração, adverte que se a Corte aguardar unanimidade da doutrina sobre os efeitos educacionais da diversidade racial, jamais encontrará um interesse governamental compulsório ${ }^{35}$.

O segundo passo do estrito escrutínio é avaliar se os programas educacionais de Seattle e Jefferson eram suficientemente adequados para atingir o interesse governamental que os propelia.

Nesse aspecto o Justice Kennedy adere ao voto da maioria, entendendo que, embora o interesse suscitado pelas autoridades educacionais fosse constitucionalmente

\footnotetext{
${ }^{31}$ Idem, pg. 37.

${ }^{32}$ Voto de Thomas, pg. 14.

${ }^{33}$ Idem, pg. 18.

${ }^{34}$ Idem, pgs. 21 e 23.

${ }^{35}$ Voto de Breyer, pg. 45.
} 
válido, a maneira como o buscavam não era apropriada o bastante para sobreviver ao exame da "estrita conformidade (narrowly tailored)".

O Chief Justice Roberts teceu diversas críticas à configuração dos programas de Seattle e Jefferson. Constatou que a utilização de nomenclaturas gerais como "não-brancos” em Seattle e "outros (que não negros)" em Jefferson reforçavam justamente uma classificação binária, que desconsiderava a diversidade racial. Para demonstrar o efeito prático do uso dessa classificação meramente dicotômica, Roberts dá o exemplo hipotético de uma escola em Seattle cuja metade dos alunos fosse branca e a outra asiática. Tal escola poderia ser considerada balanceada, ao passo que uma escola que contasse com 30\% de alunos asiáticos, 25\% de alunos negros, $25 \%$ de alunos latinos e $20 \%$ de alunos brancos não seria considerada diversificada ${ }^{36}$.

Outro ponto considerado por Roberts como falho era o parâmetro utilizado pelas escolas para determinar a proporção de alunos de cada raça a ser buscada. Ocorre que os distritos educacionais tomavam por base a distribuição racial da região onde estavam localizadas as escolas. Para Roberts, isso significava que os programas não buscavam a diversidade, mas sim o balanceamento racial conforme encontrado naqueles locais. Se o balanceamento por alguma razão se alterasse, também com ele alterar-se-iam as concepções de diversidade das escolas.

Mas talvez o mais precioso argumento levantado contra os programas de Seattle e Jefferson seja aquele da individualização. Conforme o precedente de Grutter, políticas de ações afirmativas devem considerar cada pessoa em separado, devem levar em conta a raça, porém dentro de uma ampla e holística análise do conjunto de características do aluno. A raça não pode ser determinante por si só. Ademais, a diferenciação entre um e outro aluno não pode ser mecânica, deve ser individualizada. O Justice Kennedy lembra do programa de seleção de alunos para ingresso na universidade que foi julgado juntamente com o caso Grutter. Trata-se de Gratz, que foi invalidado pela Suprema Corte em razão de sua premente mecanicidade e desconsideração para com as características individuais dos alunos. Para Kennedy, se Gratz for considerado como parâmetro, os programas de Seattle e Jefferson devem obrigatoriamente ser invalidados ${ }^{37}$. Também esse Justice entende que os distritos educacionais falharam em demonstrar que haviam procurado outras medidas de desegregação que fossem menos ríspidas e abertamente discriminatórias.

O Justice Breyer dedicou enorme espaço em sua decisão à detalhada análise do histórico de Seattle e Jefferson no combate à segregação racial. Sob esse aspecto, e considerando que o teste da estrita conformação exige justamente conhecer de perto os programas que se está julgando, o voto de Breyer foi o mais responsável dentre todos. Ele relatou aquilo que foi experienciado em ambos locais nos últimos trinta anos, dividindo os fatos em períodos, como o "Pré-decreto judicial", em Jefferson. Demonstrou um esforço contínuo e dedicado por parte dos comitês educacionais desses lugares no sentido de ampliar o contato entre alunos de diferentes raças,

\footnotetext{
${ }^{36}$ Voto de Roberts, pg. 15.

${ }^{37}$ Voto de Kennedy, pg. 12.
} 
principalmente negros e brancos. A verdade é que a crítica de Roberts quanto à polarização da classificação desses programas merece crédito apenas em parte. Realmente, hoje os norte-americanos enfrentam o problema da discriminação dos latinos, que suplantaram os negros como minoria racial com maior proporção da população nacional. Mas o verdadeiro problema enfrentado desde Brown sempre foi o racismo ao qual foram submetidos os negros. Essa era a preocupação das escolas quando iniciaram seus programas de desegregação racial. Breyer aponta para o fato de que os esforços sinceros desses comitês educacionais, eleitos pelos próprios cidadãos, devem ser objeto de respeito. Ao longo dos anos, foram experimentados métodos como a construção de novas escolas, o transporte obrigatório por meio de ônibus para levar alunos negros até as escolas antes exclusivamente brancas, a reorganização dos limites dos distritos educacionais, entre outros, todos sem o sucesso que os programas ora em questão lograram atingir.

Breyer sumariza os motivos pelos quais são estritamente configurados os programas de Seattle e Jefferson: o uso limitado e historicamente decrescente que fazem da raça como critério, a forte dependência dos programas em outros elementos não raciais, sua história e a maneira como desenvolveram e modificaram seu método, a comparação com os planos anteriores e a inexistência de alternativas razoavelmente evidentes ${ }^{38^{3}}$.

Quanto ao uso da distribuição racial local como parâmetro para buscar a diversidade nas escolas, Breyer aponta que tal prática é prevista inclusive em leis federais, além de ser adotada por diversos outros programas. Sustenta ele que não há alternativa e é justamente por isso que o Chief Justice falhou em encontrá-la.

A discussão dos Justices seguidamente foca-se no precedente estabelecido em Brown. Tanto a maioria como a minoria tentam atrair para si o papel de fiéis seguidores daquele precedente. O Justice Thomas alonga-se em comparação que faz dos argumentos de Breyer com aqueles sustentados pelos vencidos no caso de 1954. Assemelha, por exemplo, a defesa que faz Breyer da deferência e respeito para com os comitês educacionais à defesa que faziam os adeptos da doutrina separate but equal do respeito aos costumes e tradições dos racistas. Como havia sido mencionado no início dessa resenha, há dois entendimentos diferentes daquilo que foi estabelecido em Brown. Alguns propalam que foi honrada a concepção do Justice Harlan no caso Plessy, e que nenhum ente governamental deve utilizar a raça como critério, não importando o fim que busca: a Constituição é colorblind (cega em relação a cor). Mas há outros que entendem Brown como um mandado de desegregação, de inclusão dos negros na sociedade, de produção de uma igualdade material ${ }^{39}$ que ainda não existe e que jamais será alcançada através da defesa ferrenha da igualdade formal.

Pode-se imputar aos Justices Roberts e Thomas a defesa da primeira concepção. É sintomático que ambos citem, ao final de seus votos, a famosa frase de Harlan: A Constituição é cega em relação a $\operatorname{cor}^{40}$. E o voto condutor finaliza ainda defendendo

${ }^{38}$ Voto de Breyer, pg. 55.

${ }^{39}$ Para uma eficaz demonstração da relação entre a igualdade material e as políticas de ações afirmativas, ver ROCHA, Cármen Lúcia Antunes. Ação afirmativa - O conteúdo democrático do princípio da igualdade jurídica. Revista Trimestral de Direito Público. São Paulo. nº 15. p. 85-99. 1996.

${ }^{40} \mathrm{O}$ constitucionalista norte-americano Laurence Tribe critica o freqüente uso das palavras de Harlan pela doutrina e jurisprudência atualmente. Ele lembra que a frase antecedente àquela que se tornou o adágio continha 
a velha idéia de que a maneira de terminar com a discriminação racial (maligna) é parar de discriminar com base na raça (aí incluído qualquer tipo de discriminação, tanto maligna quanto benigna).

É seguro dizer, por outro lado, que os Justices Breyer, Kennedy e Stevens adotam o segundo entendimento do precedente de Brown. Em seu curtíssimo voto, Stevens lembra a posição da Suprema Corte diante da decisão de um juiz federal que, em 1968, afirmou ser irônica a tentativa de utilizar a Cláusula de Igual Proteção da $14^{\mathrm{a}}$ Emenda para invalidar programas educacionais que visavam a integração racial através do uso de discriminação racial benigna ${ }^{41}$. Naquela época, ao julgar recurso que impugnava a decisão do juiz federal, a Corte sequer analisou seu mérito, inadmitindo-o de imediato. Stevens elogia a Corte de então por ser mais fiel ao ideal de Brown e garantiu que nenhum dos Justices que integravam o órgão quando ele neste ingressou, em 1975, teria se posicionado como fez a maioria no presente julgamento.

Breyer termina seu voto alertando para os nefastos efeitos do voto da maioria. Conforme ele, os Estados Unidos voltarão a enfrentar uma onda de ódio racial exacerbado, pois a anulação de programas educacionais como aqueles de Seattle e Jefferson causarão a reversão da integração racial alcançada nos últimos trinta anos graças à adoção de métodos e critérios racialmente conscientes. De fato, o anexo ao voto de Breyer contém dados estatísticos que atestam um recrudescimento recente da segregação racial. Para Roberts e Thomas, a Constituição não se importa com a segregação de facto. Para Breyer e Stevens, ela sim se importa, e a Suprema Corte deve agir para proteger desse mal tanto brancos como negros.

Felizmente, a tendência é que seja adotada como precedente não a visão extremada de Roberts e Thomas, mas sim aquela mais ponderada de Kennedy. Este Justice fez com que uma maioria de 5 contra 4 reconhecesse como válido o interesse das escolas em buscar voluntariamente a desagregação racial. O que decidiu o caso foi a análise da estrita conformação, que nada mais é que uma averiguação do caso concreto, mas não a validade ou não do interesse governamental compulsório. Dessa forma, assim como havia acontecido em Bakke $e^{42}$, o caminho segue livre para que os comitês educacionais norte-americanos busquem alcançar a diversidade e a integração racial, restando apenas analisar, em cada situação, a rigorosa adequação de seus programas. Precipitados, portanto, aqueles que anunciavam o fim das ações afirmativas.

uma aberta declaração da supremacia da raça branca. Tribe, Laurence H.. American constitutional law. 2. ed. New York, N.Y: Foundation Press, 1988.

${ }^{41}$ Voto do Justice Stevens, pg. 4.

${ }^{42}$ Naquela ocasião, ao desempatar o julgamento com seu voto de Minerva, o Justice Powell invalidou aquela específica política de ação afirmativa, porém reconheceu como constitucional o interesse das universidades em buscar um corpo discente racialmente diversificado. Para um estudo competente e detalhado do caso Bakke na doutrina brasileira, bem como, ademais, uma excelente obra sobre ações afirmativas, ver GOMES, Joaquim B. Barbosa. Ação afirmativa \& princípio constitucional da igualdade. São Paulo: Renovar, 2001. 